\section{Sporogenesis in the Bryophyte Anthocerosis: Features shown by Fluorescence Microscopy}

FudoREsCENCE microscopy has been found useful in bacterial identification, clinical diagnosis, fluorescent antibody techniques, and general cytological studies". Recently, Shellhorn, Hull and Martin ${ }^{2}$ have extended the use of fluorescence microscopy to the detection of frosh and fossil pollen grains by using autofluorescence of exines.

In an investigation of sporogenesis in Anthoceros hawaiensis Bartlett and related genera, fluoresenco microscopy has proved useful in the dotection of incipient deposition of the exosporium in the tetrad inmediately following moiosis. In preparing the sporogenous tissuo for examination, a median bisection of the living sporophyte was placed in distilled water on a glass slide and covered with a No. 1 cover glass. No fluorochrome was added.

The material was illuminated by an incident ultra-violet light from an Osram ' $H B$ ' $200-\mathrm{W}$ mercury lamp with current supplied from a 'Universal' light source, model 250. Observations were made through a Leitz "OrthoLux' microscopo. Filters used during the illumination by ultra-violet light were $B G 38, B G 12$ and an ocular blueabsorbing filter.

In Fig. 1, two sporocytes are shown as they appoar under incandescent illumination. One sporocyte (top) has just formed tetrads, while the one below contains the four chloroplasts which are prominent in the pro-meiotic condition. The same field (Fig. 1 reversed) is shown in Fig. 2, but under ultra-violet illumination. In Fig. 2, the sporocyto containing the tetrad (top) shows tho brightly autoluorescing exosporia of the individual spores; this layer shows a greenish-yellow autofluorescent. The exosporium of developing spores and maturo spores shows this same greenish-yellow autolluorescence even after the spore is released from the ruptured sporocyte wall. The sporocyto wall itsolf is not autoluorescent. In the pro-moiotic sporocyte subjected to fluoresenee, only the four chloroplasts can be seen bocause of the red autofluorescence of chlorophyll.
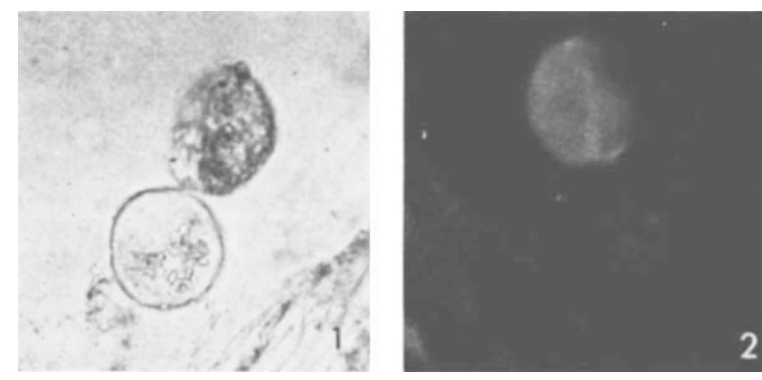

Fig. 1. Two living sporocy tes under incandescent illumination. The post-moiotic sporocy te (top) contains a tetrad and the pre-mciotic sporo-

Fig. 2. Same field (reversed) as Fig. 1, but under ultra-violet illumination. 'The strong autofluorescence shows the exosporia of the tetrad in the post-melotic sporocy te (top); whereas only the four chloroplasts of the $(\times$ c. 770$)$

The phenomenon of autofluorescence in the exosporia of Anthoceros suggests that fluorescence microscopy may well be useful in investigations of sporogenesis among other bryophytes. Similar observations of other species of the same genus and representatives of other orders of bryophytes were made. Autofluoresence within tho exosporium was found in the following species: Reboulia hemisphaerica, F'ossombronia salina Lindb, Anthoceros laevis L., and Anthoceros punctatus I. With this tochnique, distinct developmental changes can easily be observed between the pre-meiotic and post-meiotic conditions. Indeed, fluorescence microscopy may also provo useful in studying exine development in angiospermous spocies. Exines of Yucca treculeana also oxhibit bright yellow-green autofluorescence. The similarity of autofluorescence in bryophyto exosporia and pollen exines suggests a homologous chemical composition.

JOHN E. RTDGWAY

D. A. LaRson

Department of Botany and Cell Research Institute, University of Texas,

\section{Austin.}

'Price, G. R., and Schwart\%, s., in Physical T'echniques in Biological Research, $3,91(1956)$.

2 Shellhorn, S. J., Hull, H. M., and Martin, ‥ \$., Nature, 202, 315 (1964).

"Goodwin, R. H., in Ann. Rev. Plant Physiol., 4, 283 (Annual Revlews Inc., Stanford, California, 1953).

\section{MICROBIOLOGY}

\section{Transformation by Hybrid DNA in Bacillus subtilis}

Doty et al. ${ }^{1}$ havo roported that when an aqueous solution of DNA is heat-denatured and then annealed by slow cooling, the complementary strands separated by the thermal troatment recombine specifically. By this mothod, Marmux and Lane" made hybrid DNA molecules in which one of the complementary strands derived from the DNA of a streptomycin-resistant strain of $D$. preumoniae, and the other strand from a wild-type strain. The hybrid molecules thus formed woro said to be functional in transforming $D$. pneumoniae to streptornyein resistance.

In certain transformation experiments Herriott ${ }^{3}$ used a molecular hybrid of tho DNA extracted separately from two strains of Hemophilus infuenzae, one streptomycinresistant and the other catornycin-resistant. He found tho number of double transformants to be significantly highes (fifty-fold) than with the control-a mixture of the two DNA materials denatured and renatured separately. This result may suggest that both strands of the hybrid molecule are cffective in expressing the information into the recipient cell. Different results were obtained by Marmur et $a \bar{l} .^{4}$ and by Kont et al. ${ }^{5}$ in $D$. pneumoniae.

Recontly, Bresler et al. ${ }^{6}$ obtained results for $B$, subtilis similar to those of Herriott. Using $h i s^{-}$and $t r y^{-}$strains as DNA donors, they observed that the hybrid DNA can. transform a double auxotrophic strain to a prototrophic one. Moreover, when DNA synthesis by recipient cells is excluded, the hybrid molecules are still able to stimulate the ability of double auxotrophic cells to synthesize histidine and tryptophan. Therefore they assume that both strands of the doublo helix can serve as templates for messenger RNA synthesis.

We report here some experiments on transformation by hybrid DNA in $B$. subtilis in the systern used by Bresler et al. The recipient strain was $B$. subtilis $S B 25$ ( his $_{2}^{-}$try ${ }_{2}^{-}$a double auxotroph for two linked markers ${ }^{2,8}$. In our experimental conditions, a 'cotransfer index' of $0.5 \pm 0.03$ was calculated. The two donor DNAs were isolated by Marmur's method ${ }^{-}$-one from a $B$. subtilis strain auxotrophic for histidine only $\left(S B 25 h i s_{2}^{-}\right)$and the second from a strain requiring tryptophan $\left(S B B_{25} t_{2}\right)$. Hybrid DNA was formed by the procedure of Schildkraut et al. ${ }^{30}$. (For more details see the legend to Table 1.) In transformation assays the mothods of Spizizen ${ }^{11}$ and Nester et al. ${ }^{8}$ were both used successfully. The most reliable results were obtained by a slight modifieation of the latter $(20 \mu \mathrm{g} / \mathrm{ml}$, of $\mathrm{L}$-histidino in CHT 2 and CHT $10 \mathrm{media})$.

Table 1 shows that the number of double transformants obtained with the hybrid DNA is significantly higher than with the control mixture. A ratio his $s^{+} y^{+} / h_{i s^{+}}$of $1 \times 10^{-2}$ may be caloulated. This value is close to that found by Brosler et al. in the same system. 